\title{
Cultural and contextual considerations in designing programs to support the incorporation of early childhood development within ongoing national nutrition programmes: A focus on the Baby-Friendly Community Initiative (BFCl) in a rural African context
}

Patricia Kitsao-Wekulo ( $\sim$ kadwek05@yahoo.com )

African Population and Health Research Center https://orcid.org/0000-0003-4206-9746

Emma Haycraft

Loughborough University

Teresa Mwoma

Kenyatta University

Kenneth Okelo

African Population and Health Research Center

Esther Kinuthia

African Population and Health Research Center

Peter Muriuki

African Population and Health Research Center

Silas Onyango

African Population and Health Research Center

Judith Kimiywe

Kenyatta University

Milka Wanjohi

African Population and Health Research Center

Elizabeth Kimani-Murage

African Population and Health Research Center

Paula Griffiths

Loughborough University

Research Article

Keywords: Baby Friendly Community Initiative, Feasibility, Nurturing care 
Posted Date: November 30th, 2021

DOI: https://doi.org/10.21203/rs.3.rs-1125126/v1

License: (c) (i) This work is licensed under a Creative Commons Attribution 4.0 International License. Read Full License 


\section{Abstract}

The Baby Friendly Community Initiative (BFCl) offers a unique platform for integration of counselling on early childhood development (ECD) with existing maternal and child health and nutrition messages. To understand how to efficiently deliver such a program, this study determined the feasibility of integrating counselling on child stimulation into the Kenyan BFCl activities. Qualitative interviews ( $N=97)$ among female (aged 15-49 years) and male users, stakeholders, and services providers in Koibatek sub-County (mainly inhabited by the Tugen people, a Nilotic group in sub-Saharan Africa) provided extensive information on understanding regarding ECD, caregiving beliefs, needs at different levels and barriers and facilitators. Contextual influences and existing health system infrastructure are important considerations when designing integrated interventions to improve nurturing care of children.

\section{Main Text}

The Baby Friendly Community Initiative (BFCl) is a global strategy recommended by the World Health Organization (WHO) to promote optimal maternal, infant, and young child nutrition (MIYCN) at the community level (World Health Organization \& UNICEF, 2018). The Baby Friendly Hospital Initiative (BFHI) (Core Group Community Health Network, 2012; World Health Organization \& UNICEF, 2009), the precursor to the $\mathrm{BFCl}$, was adopted by Kenya in 2002 as an effective intervention for promoting optimal

breastfeeding practices. However, the BFHI was limited in reach as more than half of the targeted women, particularly the very poor, delivered at home. The BFCl, which applies the principles of the BFHI and extends the follow up and care of the mother and child to the community, was adopted by the Kenyan government in the 2007 Infant and Young Child Feeding (IYCF) Strategy. The implementation guidelines were adopted in 2016, and the BFCl has been successfully implemented in several counties (Kavle \& Ahoya, 2019; Ministry of Health ( $\mathrm{MoH})$ Kenya, 2016). The principal objectives of the $\mathrm{BFCl}$ are to increase the proportion of exclusively breastfed babies, and to sustain breastfeeding after six months alongside the introduction of complementary foods. The $\mathrm{BFCl}$ is effective in promoting infant breastfeeding and complementary feeding as well as optimal maternal and child health outcomes (Kavle et al., 2019; Kimani-Murage et al., 2021; Maingi, Kimiywe, \& Iron-Segev, 2018).

In Kenya, as in many sub-Saharan African settings, young children in resource-constrained contexts live within unstimulating home environments which hamper their achievement of their developmental potential (Black et al., 2017). As early stimulation among young children is a strong determinant of future outcomes (Walker et al., 2015), it is important to ensure that these children receive the best possible chance for optimal development. Integrated interventions addressing both early child development and nutrition are essential for improving infant and young child outcomes (Grantham-McGregor, Fernald, Kagawa, \& Walker, 2014; Powell, Baker-Henningham, Walker, Gernay, \& Grantham-McGregor, 2004; Walker et al., 2015). The sixth step of the BFCl 'encourages mothers to continue breastfeeding their children up to 2 years and beyond, in conjunction with the appropriate, adequate and safe complementary feeding while providing holistic care and stimulation of the child.' This stipulation makes the BFCl ideal for incorporating messages from the Care for Child Development (CCD) package (UNICEF, 2015), alongside 
feeding, health and nutritional messages. The recommendations within the CCD package provide ideas for play and communication activities to help children to learn and to grow, and help caregivers feel more important in the lives of their young children.

The African Population and Health Research Center (APHRC) conducted a pilot study in Koibatek subCounty in Baringo County (where the BFCl has been established by the Ministry of Health [MoH]) from 2014 to 2016 to determine the feasibility and effectiveness of the BFCl in Kenya (Kimani-Murage et al., 2015). The study results indicated that the $\mathrm{BFCl}$ was effective in promoting optimal infant feeding as well as in improving maternal and child health outcomes in a rural setting (Kimani-Murage et al., 2021). The results also showed that counselling by community health volunteers (CHVs) and support received through monthly group meetings enhanced women's skills and competence in infant feeding which in turn led to better practices.

The Kenyan $\mathrm{MoH}$ as well as other sector stakeholders seek to support the holistic development of young children. In view of this, they questioned the focus on nutrition and health status alone by child health programs, such as the $\mathrm{BFCl}$, with no attention being paid to any aspect of early child stimulation and learning opportunities. Moreover, there is a generalized lack of knowledge around the cultural and contextual factors that need to be considered in the design of programs to support early childhood development (ECD), particularly in rural Kenya. The recognition of the BFCl as a unique platform for integration of IYCF messages into other health areas and offering opportunities for counselling families around ECD has been highlighted in the past (Kavle et al., 2019). It is therefore necessary to understand how to efficiently deliver a program to enhance child stimulation using an existing national health and nutrition program, such as the $\mathrm{BFCl}$. The follow-up study reported in this paper hence sought to determine the feasibility of integrating counselling on child stimulation into the $\mathrm{BFCl}$ activities in Kenya. The study (referred to as the feasibility study henceforth) had the following specific aims: 1) To describe participants' current ECD knowledge, attitudes, and practices; 2) To understand how local contexts and cultural factors influence child development and nurturing care practices; 3) To understand user, stakeholder and service provider needs for incorporating parental support for nurturing care into the BFCl; and 4) To explore opportunities for and existing gaps in program implementation.

\section{Methods}

\section{Study design}

The feasibility study reported here was qualitative in nature and was part of a larger one that was an extension of the earlier BFCl study in Koibatek sub-County of Baringo County in the North Rift region of Kenya conducted between 2014 and 2016 (Kimani-Murage et al., 2015; Kimani-Murage et al., 2021). The data for the feasibility study were collected in July 2018 , before the larger study undertook training on the CCD modules with local healthcare workers. An ecological approach was used to assess the social context in which the intervention operated.

\section{Study site and participants}


Koibatek sub-County is one of the six sub-counties in Baringo County. The total population in 2014 was 125,637 with $24 \%(30,203)$ being women of childbearing age $(15-49$ years) and $4 \%(4,799)$ being children aged under one year. The sub-County is inhabited by the Tugen people, a Nilotic group whose main occupation and economic activity is mixed farming. The stable economic situation in the sub-County makes it relatively more secure than the surrounding sub-counties. There are 32 public health facilities within Koibatek sub-County of which 26 are dispensaries, five are health centers and one is the subCounty or District Hospital. The sub-County has one medical consultant, six medical doctors, 31 clinical officers of various specialties and 132 nurses. There are three nutrition officers serving the entire subCounty. Slightly more than half $(53.8 \%)$ of the deliveries in the entire county are assisted by a skilled health professional (Kenya National Bureau of Statistics (KNBS), Ministry of Health/Kenya, National AIDS Control Council/Kenya, Kenya Medical Research Institute, \& National Council for Population, 2015).

The feasibility study included women of reproductive age (15-49 years) who participated in the earlier $\mathrm{BFCl}$ study and who had children aged between 0-36 months. Children's primary caregivers who in the current report are referred to as 'users' were mostly their biological mothers. Other users included fathers and grandparents. Participants at the community level included CHVs (service providers), village elders, other community leaders including chiefs, women, youth, and religious leaders (stakeholders). At the national and sub-national levels were members of the sub-County Health Management Team (SCHMT; considered as both service providers and stakeholders), and ECD stakeholders including government officers from the $\mathrm{MoH}$, directorate of ECD services and ECD service providers. Purposive sampling was used to identify or recruit the eligible participants until data saturation was reached and no new ideas were identified.

\section{Data collection tools and procedures}

During the feasibility study, we conducted focus group discussions (FGDs) and in-depth interviewers (IDIs) with users (caregivers including fathers and grandmothers) and service providers (CHVs); and key informant interviews (KIls) with service providers (SCHMT members) and other stakeholders. Qualitative interview guides were used with users and service providers to capture information on breastfeeding and young child feeding practices, ECD knowledge, attitudes, and practices and early stimulation to provide an understanding of the influence of local contexts and prevailing cultural factors on child development and nurturing care practices. We also explored user, stakeholder and service provider needs in incorporating nurturing care into the $\mathrm{BFCl}$ at household, community, and societal levels. We asked users, stakeholders and service providers about strategies that could be used to meet identified needs. To enhance our understanding of the opportunities for and gaps in program implementation, we asked service providers about their experiences with other related programs. We also asked service providers and other stakeholders about potential barriers to and facilitators of implementation of an intervention that sought to incorporate parental support for nurturing care into the $\mathrm{BFCl}$.

Qualitative data collection was carried out by interviewers with relevant college-level education, and with experience in conducting qualitative interviews. All data collectors were residents of the study area and 
fluent in English, Kiswahili, and the local language. After recruitment, data collectors were trained for one week on ethical issues, data collection procedures, and data quality. The training was both information and problem-solving based.

Qualitative interviews were conducted as follows: seven FGDs with users (including mothers and fathers with children under the age of 36 months, and grandmothers) and service providers (CHVs); 37 key informant interviews (KIIs) with stakeholders (such as county and sub-county officers in the Children's and ECD Departments) and service providers (ECD providers and teachers, CHVs, organizations working within the ECD sector, nutrition and community health strategy departments); and, six IDIs with service providers (CHVs) and users. The FGDs, which had between six and eight participants $(\mathrm{N}=54)$, were conducted face-to-face in a group setting while the KIls and IDIs were completed in-person on an individual basis. The FGDs and IDIs were led, guided and monitored by a trained moderator who was a member of the data collector team. During the FGDs, the moderator was accompanied by a note-taker whose role was to welcome the participants, audio record the interviews and take notes. The KIls were conducted by a member of the research team. Appointments were made beforehand, and efforts were made to ensure that the venues used were accessible, comfortable, private, quiet and free from any distractions. Before the interviews began, the moderator established the language with which the participants were most comfortable. All the interviews were audio recorded.

\section{Ethical considerations}

The study received ethics approval from the Amref Health Africa's Ethics and Scientific Review Committee (ESRC) after internal review at the APHRC. We also received permission to conduct the study from the National Commission for Science, Technology and Innovation (NACOSTI) before the study began. A rigorous community mobilization process was followed to inform the community and the caregivers who had participated in the earlier study. Permission to conduct the proposed study was sought and obtained from the community chiefs and village elders. Individual informed consent was sought and obtained from all adult participants following full disclosure regarding the purpose of the study and the procedures involved. Written informed consent forms were signed by the study participants. For those that could not read, oral informed consent was obtained. Women aged between 15 and 17 years old with children were considered emancipated minors and underwent the informed consent process like the others.

\section{Data analysis}

The data were analyzed using the Framework Method process outlined by Gale and colleagues (2013). All the interviews were transcribed verbatim and concurrently translated into English. Using an inductive approach (Thomas, 2006), we coded the data using pre-defined codes that consisted of ideas, concepts, behaviors and interactions in order to classify all the data and make them easier to organize and retrieve. Members of the research team independently coded transcripts that had been assigned to them. An 'other' code was used for those data that did not fit under the pre-defined codes. A list of key ideas was then developed by grouping the codes into categories to explain the findings guided by an explanatory framework which was informed by the derived data. After coding, patterns of meaning (themes) were 
identified and connections were made to facilitate a systematic comparison (Gale et al., 2013). The themes were compared to the dataset to ensure that they were accurate representations of the data. At the final stage, a matrix was developed, and the data from each transcript were summarized by category (charting). The chart included interesting or illustrative quotes that enabled us to describe the data using the participants' own subjective frames and expressions. Apart from being a practical way to reduce and interpret the data, one of the advantages of the Framework Method is that it enabled all members of the research team to engage with the data and offer their perspectives during the analysis process without having to read all the transcripts.

\section{Results}

The themes identified from the data were categorized under four main headings to align with the aims of the study: (i) Knowledge, attitudes, and practices on ECD and early stimulation; (ii) Contextual and cultural influences on child development and nurturing care practices; (iii) User, stakeholder and service provider needs for incorporating parental support for nurturing care into the $\mathrm{BFCl}$; and (iv) Opportunities for and existing gaps in program implementation. The first main heading provided information on the study context in relation to ECD knowledge, attitudes and practices. The sub-themes under the second main heading included cultural factors that influence child development and nurturing care practices. Under the third main heading, the sub-themes included household, community and societal needs; and strategies and recommendations for incorporating parental support for nurturing care into the BFCl. Under the fourth main heading, themes were concerned with potential facilitators and barriers to program implementation.

\section{Knowledge, attitudes, and practices on ECD and early stimulation}

It was important to gain an understanding of the characteristics of the study context, including awareness of existing knowledge, attitudes, and practices around ECD and early stimulation.

Understanding this enabled us to determine what knowledge and attitudes caregivers had about ECD, and the practices they engaged in at the time of the study. In addition, this information also enabled us to establish existing gaps which provided the basis for considerations of what to include in a training package on CCD within the Kenyan context to effectively integrate support for nurturing care.

The concept of ECD had different connotations for various participants. Primary caregivers mentioned that it encompassed child growth, proper hygiene, appropriate feeding including exclusive breastfeeding, and child health. Some mothers were aware that child development took place in stages (Table 1). The reports from fathers suggested that their understanding of ECD was in terms of a child's ability to communicate different needs, such as hunger, through crying. CHVs believed nurturing care covered aspects of children's healthy growth from conception to delivery, and proper care and feeding (exclusive breastfeeding and complementary feeding) of the child. They mentioned that children who received optimal care developed rapidly and did not get ill often and were able to easily grasp different concepts when they got to school-going age. 
Primary caregivers, mostly mothers, seemed to be aware of their role in fostering play, as they provided shop-bought play items, or those improvised from locally available materials for their children. Caregivers used different forms of engagement including showing children how to throw things, teaching them how to clap, singing songs, counting numbers, telling them stories, dancing and pointing out and naming objects as teachable moments. In addition, primary caregivers reported having structured play time where they engaged in 'serve and return' tasks with their children, such as passing balls back and forth. Some of the play activities reported seemed to be incidental or occurring naturally as they took place during routine day-to-day activities. However, even though they acknowledged the importance of play, caregivers reported that they had limited time for playing with children. House helps and older siblings bridged that gap by playing with the children for longer periods than the primary caregivers were able to. Primary caregivers considered it acceptable for adults to play with young children and recognized the benefits of play as promoting a positive relationship and bonding between the child and their caregiver, provision of stimulation, enabling children to learn new skills and enhancing brain development among children (Table 1). Conversely, some respondents expressed some concerns, and their reasoning was that some adults had ill intentions while playing with young children.

Fathers reported that they engaged in different types of activities with their young children such as playing with balls, pretend games or running games. Fathers also read stories to their children, talked to them when they were still very young and communicated through gestures even if the children were not able to respond verbally. Fathers reported that their communication with young children was aimed at disciplining them. Like mothers, fathers postulated that engaging in play activities with the child fostered bonding and improved their relationship (Table 1).

Grandmothers reported that they engaged in activities such as training young children how to walk by holding their hands and massaging the legs of children who had delays in walking with petroleum jelly to straighten them. Grandmothers also reported that they provided children with toys, showed them how to carry out certain activities like beating drums, sang to children and taught them about the alphabet and religion (Table 1).

Although there was a varied understanding of ECD among the different participants, most of the meanings were closely related and seemed to be informed by their own personal experiences with young children, as well as from their interactions with CHVs. Establishing participants' current levels of ECD knowledge, attitudes and practices provided a good starting point for identifying information and behavior gaps to be considered in the incorporation of nurturing care into the $\mathrm{BFCl}$.

Table 1. Knowledge, attitudes and practices on ECD 


\begin{tabular}{|c|c|}
\hline Concepts & Quotes \\
\hline $\begin{array}{l}\text { Knowledge on } \\
\text { ECD }\end{array}$ & $\begin{array}{l}\text { "We are told when a child reaches around } 6 \text { months they start to sit down; when } \\
\text { they reach } 9 \text { months, they start to stand; and then after there, they start to grow } \\
\text { teeth; ;...then } 9 \text { to } 12 \text { months, they will start standing properly and walking slowly } \\
\text { and then when it reaches } 1 \text { year to about } 1 \text { and a half, they walk properly... they } \\
\text { start speaking one word until when they will speak properly." IDI, mother, Simotwet }\end{array}$ \\
\hline Benefits of play & $\begin{array}{l}\text { "There are those that can play with the child in a bad way but as a parent I will } \\
\text { play with them such that they will be active. They might become stupid if I don't } \\
\text { play with them." FGD, mothers, Shauri }\end{array}$ \\
\hline $\begin{array}{l}\text { Concerns about } \\
\text { adults playing } \\
\text { with children }\end{array}$ & $\begin{array}{l}\text { "Of late there is a worry about the interaction of children with other people. There } \\
\text { are areas that have liquor dens and children can be abused there because the } \\
\text { father is not around and the child might be taken by someone. Sometime back, } \\
\text { there were concerns over the incidences you hear about people committing funny } \\
\text { things to children. Almost three years ago I heard once or twice a small child had } \\
\text { been raped." KII, ECD providers, Shauri }\end{array}$ \\
\hline $\begin{array}{l}\text { Communication } \\
\text { with young } \\
\text { children }\end{array}$ & $\begin{array}{l}\text { "You must talk to a child that is still small, even if they don't understand ...you also } \\
\text { show them any signs, you tell them, until eventually this child grows to understand } \\
\text { everything." FGD, fathers, Arama }\end{array}$ \\
\hline $\begin{array}{l}\text { Positive effects } \\
\text { of play }\end{array}$ & $\begin{array}{l}\text { "... When a child is playing, as a parent, you are supposed to be playing together. } \\
\text { You teach the child, you play together, and the child will be happy and will think } \\
\text { positively about you ... when you arrive home, the children run to you. You will also } \\
\text { have a good relationship between you and the children. When the children see you, } \\
\text { they will know that this is their father." IDI, Father, Arama }\end{array}$ \\
\hline $\begin{array}{l}\text { Learning } \\
\text { through play }\end{array}$ & $\begin{array}{l}\text { "I teach them about God and singing. I also teach them the alphabet i.e. (A, B, C, } \\
\text { D). They rehearse. We also pray. When you are with them, you teach them such } \\
\text { stuff. Every evening, the children I stay with tell me to go and sing with them in the } \\
\text { sitting room. Our main activity there is to sing, jump and pray. I.. pray for them in } \\
\text { Swahili since children nowadays are speaking in Swahili." FGD, grandmothers, } \\
\text { Makutano }\end{array}$ \\
\hline
\end{tabular}

\section{Contextual and cultural influences on child development and nurturing care practices}

We sought to establish the contextual and cultural influences on child development and nurturing care practices and the extent to which participants perceived those practices as promoting nurturing care.

\section{Local contexts and cultural factors that influence child development}

There were several traditional beliefs and practices reported among participants that influenced the care of young children and that were likely to be important considerations when incorporating parental support for nurturing care into the BFCl. The beliefs held by community members covered different areas such as one's interactions with young children, feeding of young children, use of traditional medicine on young children and the general care of young children. Some of the beliefs centred around gendered behaviors that recommended differential treatment of boys and girls. Other beliefs were harmful while others were used to explain events which did not seem to have a known cause. 
Grandmothers believed that traditional herbs and medicines should be administered to young children alongside breastfeeding within the first six months of life for optimal growth and development. Fathers mentioned that when a child cried throughout the night, it was because a person with ill intentions had looked at them with a 'bad' eye. Healthcare providers also reported that community members believed that a child became bewitched when someone looked at them 'badly' (Table 2).

Beliefs related to gender socialization were that boys should not be wrapped when they were small as it could interfere with proper development of their genitalia; that clinics were only for women and therefore men should not accompany their wives during health facility visits; and, that children under a certain age were the responsibility of their mothers (Table 2). Some of these beliefs barred men from taking part in childcare activities. According to sub-county officials, men still held onto the traditional practice of having their pregnant wives accompanied to the health facility by female relatives such as mothers, mothers-inlaw, sisters, and sisters-in-law.

Religious beliefs around the care of young children resulted in some parents keeping their children away from school, not allowing their children to take medicine when ill, or not allowing immunization. ECD providers reported that in such cases, they took the children to the clinic for immunization against the parents' wishes and then told parents that it was a directive from the government. Some pregnant women also did not attend antenatal clinics as it was against their religious teachings. Some children with disabilities were given traditional medicine because the parents did not believe in hospitals.

Several myths and misconceptions regarding the care of young children were reported by community members. One was the belief that immunization is bad (Table 2) and that children should not take milk and eat meat. Other myths reported were that children became sick if they were given names that they 'did not like' and that people should only wash their hands with liquid soap (for them to be considered clean).

Table 2. Traditional beliefs and practices 


\begin{tabular}{|c|c|}
\hline Concepts & Quotes \\
\hline $\begin{array}{l}\text { Use of } \\
\text { traditional } \\
\text { herbs }\end{array}$ & $\begin{array}{l}\text { "When grandmothers of small children come to visit a child and see their health is not } \\
\text { good, they say that the child needs to be given medicine ... old medicine, that is } \\
\text { traditional medicine. They go to the forest to look for the medicine for the child so } \\
\text { that he/she gets good health." FGD, fathers, Arama }\end{array}$ \\
\hline \multirow[t]{2}{*}{ 'Bad' eye } & $\begin{array}{l}\text { "You may find the child crying overnight, and you are told the child is crying because } \\
\text { someone who is not good came and looked at him with a 'bad eye.'... it is better for } \\
\text { the child to stays indoors; the child should not be brought outside." FGD, fathers, } \\
\text { Arama }\end{array}$ \\
\hline & $\begin{array}{l}\text { "You find some people saying someone with a 'bad eye' has looked at my child. } \\
\text { Maybe someone made a visit and the child became sick, so there will be questions } \\
\text { and domestic squabbles. ...they believe that someone might have bewitched their } \\
\text { child." KII, healthcare provider }\end{array}$ \\
\hline $\begin{array}{l}\text { Gender } \\
\text { socialization }\end{array}$ & $\begin{array}{l}\text { "... When their children are small, some parents do not want to wrap them, if they are } \\
\text { boys. They say that male children are not wrapped.... a parent leaves the child to } \\
\text { mess himself as she does not want to wrap the child." KII, ECD provider }\end{array}$ \\
\hline \multirow[t]{3}{*}{$\begin{array}{l}\text { Perceptions } \\
\text { on gendered } \\
\text { roles }\end{array}$} & $\begin{array}{l}\text { ".. our role as men especially when the child is young, under } 3 \text { years, there is nothing } \\
\text { much we can contribute. Mostly it is the woman who does that work. We men are not } \\
\text { at home the whole day, and most of the time we come back in the evening. That is } \\
\text { when you can spend some time with the child. When you arrive you hold them, let's } \\
\text { say when the mother has gone to prepare food. However, most of the time we do not } \\
\text { have time. If the mother tells you that the child needs some items or that his health is } \\
\text { not good, that's when you think of how you can help. Most of the time, when the child } \\
\text { is okay, we do not consider it our responsibility when the child is at that age."IDI, } \\
\text { father, Toniok }\end{array}$ \\
\hline & $\begin{array}{l}\text { "I think maybe they usually think a child belongs to the mother, so it is the } \\
\text { responsibility of the mother to take care..." KII, ECD Teacher, Makutano }\end{array}$ \\
\hline & $\begin{array}{l}\text { "You find that culture especially in this community where we come from, majority of } \\
\text { the people in Koibatek now, majority are Kalenjins, then Kalenjins have their own } \\
\text { culture, when we talk about support, even the mother to the health facility, they don't } \\
\text { believe in that, they know whoever is supposed to be with the mother especially when } \\
\text { expectant or even when carrying this baby is the mother in-law or the sister in- } \\
\text { law..." KII, sub-County Nutritionist, Eldama Ravine }\end{array}$ \\
\hline $\begin{array}{l}\text { Health- } \\
\text { related } \\
\text { beliefs }\end{array}$ & $\begin{array}{l}\text { "There is an immunization that is harming children. That is what is being rumored. } \\
\text { Some children are getting sick after being immunized. Some children are unable to } \\
\text { speak after immunization. The children just keep quiet after immunization. They } \\
\text { refuse to talk." FGD, grandmothers, Makutano }\end{array}$ \\
\hline
\end{tabular}

\section{User, stakeholder, and service provider needs for incorporating parental support for nurturing care into the $\mathrm{BFCl}$}

Participants were asked about their needs in relation to incorporating parenting support for nurturing care into the BFCl. The FGDs and KIls revealed that users, stakeholders, and service providers had multidimensional needs which were framed at the household, community, and societal levels. 
Participants also suggested some strategies and made recommendations on how to incorporate parental support for nurturing care into the BFCl.

\section{Household, community, and societal level needs}

The need to promote good caregiver health and nutrition to enhance their ability to provide nurturing care for their children was reported at the household level. This was considered very important as poor caregiver health and nutrition resulted in them not being able to take proper care of their children (Table 3). For instance, some mothers and fathers mentioned that those who were breastfeeding were more likely to give their children other foods before the age of six months if they felt they did not have enough milk because of poor health. The need for knowledge on how to take care of their families and ensure their welfare was mentioned in the FGDs with fathers, and was considered critical, especially among new fathers.

The need for a strong social support system to provide different types of support was mentioned by grandmothers and CHVs. The lack of a social support system resulted in grandmothers being left with the full responsibility of taking care of their grandchildren and yet some of them were not able to meet all the demands of care for young children because of their advanced age. Poor health of grandparents also rendered them incapable of providing optimal care for young children. Such conditions made it difficult for grandmothers to support integration of nurturing care for young children into the BFCl.

At the community level, CHVs and healthcare providers noted the need for caregivers to ensure adherence to regular antenatal visits and take their children to the clinics for immunization and growth monitoring. This would ensure the timely identification of children with any issues with regards to their nutrition and health status (Table 3). One challenge that CHVs mentioned in relation to this was caregivers' reluctance to visit health facilities for regular check-ups because of the fear of being tested for HIV (which is a requirement during antenatal visits). The need for adequate support for breastfeeding mothers while they were at home was also mentioned. As reported during the FGDs, some breastfeeding mothers did not get enough food, likely due to poverty, and because of being overburdened with competing tasks such as household chores, and taking care of young children, they did not get enough rest. This situation resulted in failure to meet children's basic needs and lack of provision of quality care. Such circumstances made it difficult for caregivers to support incorporation of nurturing care into the $\mathrm{BFCl}$, as they would be concerned with taking care of their basic needs, rather than developmental needs of young children. ECD providers mentioned the need to sensitize men on the importance of them being jointly involved in child rearing activities, as this would promote the holistic development of the child (Table 3). CHVs mentioned the need for inclusivity, as children with disabilities remained ignored within the community and their requirements were not catered for. CHVs also pointed out the need to incorporate cultural considerations in health messaging as in some cases, traditional beliefs contradicted healthcare worker messages which made community adherence difficult.

Policy makers revealed that they felt it was very important to have good policies in place to provide direction in incorporating parental support for nurturing care of young children. They mentioned that 
proper implementation of such policies would promote the optimal growth and development of young children. The development of an implementation plan for the relevant policies would also be helpful in outlining the process of integration of nurturing care into the BFCl. For instance, the Breast Milk and Substitutes Act prohibits the advertisement of breastmilk substitutes at healthcare facilities. In line with this, policy makers identified the need for financial resources to promote proper implementation of policy guidelines, and that these could be obtained through partnerships with relevant stakeholders. Investing in personnel was another need which, if met, would ensure implementation of issues that would promote ECD. Healthcare workers reported that the availability of personnel to assist with the additional workload that comes with incorporating ECD messages could facilitate the successful integration into the BFCl. Policy makers also mentioned the importance of a multisectoral approach to enhance collaboration and a common understanding among the different players to promote efficient implementation of specific ECD activities (Table 3).

Table 3. Household, community and societal needs 


\section{Concepts Quotes}

Household "A mother has to be taken care of by the father so that when the mother is happy, even level needs her milk lets down properly and she will be able to breastfeed the child.... if she goes to the farm and comes back without being fed, that is what will be a problem. We as men we have to take care of the mother and then after taking care of the mother, the mother will be able to take care of the child."FGD, fathers, Tugumoi

Community level needs
"At the moment children are supposed to be monitored from 0-5yrs. However, after they finish immunization, their caregivers don't bring them to the facility for monitoring as they believe they are done. This is an area which we need to focus on because we can identify children who are not doing well in terms of their nutrition and health. We can then intervene." IDI, healthcare provider

"Men need to be sensitized, to know that upbringing of a child does not depend on one person; it depends on all people so that she/he grows and be healthy." KII, ECD provider, Toniok
Societal level needs
"Well with good policies we expect that they would give direction on how a child should be cared for in order to develop well, particularly if they are implemented to the letter. I want to take for you for example through the policy on breastfeeding. There is ... the Breast Milk and Substitute Act which bars ... advertisements of milk substitutes apart from breast milk within a facility. So if for example staff are made aware of that particular policy and they implement it, then we are very sure that children will be exclusively breastfed, and a child will be breastfed up to 2 years .... We expect a positive impact on the growth of this child." KII, policy maker

"...there is need to invest in personnel. Once we get more personnel, I believe that issues of ECD will be handled better.... the other thing is... once the resources are available in terms of money, I know actually we can do better." KII, policy maker

"...and each and every partner needs to play their roles. Maybe the government, the county government, central government, and everybody even the education, agriculture, and health sectors need to come up and own that particular policy and implement it. You know the problem is Kenya we have got a lot of policies but we don't implement them." KII, policy maker

"...the various players need to have a common implementation so that we don't get education, health and agriculture implementing issues of ECD differently... and we get the department of children not even aware of what health is doing .... all the players need to be brought together and be educated on this particular policy so that during the implementation, everybody knows his/her role at different stages because not all of us will implement at the same level..." KII, ECD official

\section{Participants' strategies and recommendations for incorporating parental support for ECD into the BFCI}

One of the strategies that $\mathrm{CHVs}$ reported using to deal with caregivers who did not take their children to the clinic was visiting homes with healthcare workers to administer home care. They mentioned that they also taught the parents what to do because there was no other form of help that they could give. CHVs reported that they encouraged mothers to express breastmilk in the cases where they needed to leave their children to go to work. In this way, CHVs built a good relationship with families that were resistant to interacting with healthcare workers at the health facilities and had a starting point for encouraging 
parental support for nurturing care. Where children had deliberately missed immunization appointments due to factors such as religious beliefs, ECD providers worked with the local administration to ensure that caregivers did not erode the health gains by denying their children immunization as this also posed a danger to other children (Table 4). Immunization was considered one of the important aspects of nurturing care which needed to be in place to promote integration.

CHVs reported on the different strategies that they used to increase male involvement so that men could also provide support for nurturing care. During home visits, fathers were also targeted for sensitization on the importance of them playing an active role in childcare, good nutrition and health for the family. One $\mathrm{CHV}$ mentioned that she encouraged men to participate in the regular public meetings. CHVs also reported that they asked men who did not get involved at home to participate in mother-to-mother support groups so that they could appreciate the importance of their engagement with their families (Table 4). $\mathrm{CHVs}$ also liaised with healthcare providers to sensitize men on the need to ensure that their families were well catered for, as once basic needs were met, then caregivers would be able to support children's need for nurturing care.

Participants offered several recommendations for incorporating parental support for nurturing care into the BFCl to improve child growth and development. ECD providers reported that male spouses could be consistently trained, sensitized and counselled through seminars to sensitize them on the importance of their involvement in child growth and development. They could also be encouraged to take care of the health of their wives from pregnancy onwards. ECD providers also mentioned that they should be supported to establish community gardens from which children under their care could get access to various foods including fruits, vegetables and eggs. ECD providers could also conduct one-on-one visits, and use community outreach programs in chiefs' barazas, women's meetings, school graduation events to sensitize caregivers of young children, particularly fathers, about the importance of promoting optimal ECD (Table 4).

$\mathrm{CHVs}$ recommended provision of stipends and work tools including identification badges, mobile phones and bags to facilitate home visits through which they could incorporate ECD counselling (Table 4). Regular monitoring of children's growth would promote optimal development. Other recommendations from ECD providers included empowering parents to join village savings associations to generate income from activities such as farming, chicken rearing among others. There was also a suggestion to discourage caregivers from giving herbal medicines to their young children, particularly those aged below six months. ECD providers felt that they had the responsibility of identifying children that had missed immunization appointments and working with caregivers to ensure that all children were immunized on schedule. Participants recommended that a referral system between ECD centers and nearby health facilities be established to ensure that children could access timely health services as needed.

Policy implementers mentioned the need to ensure proper implementation of existing policies. Another recommendation was the establishment of a county level steering committee to coordinate nurturing care 
activities. They also recommended refresher trainings for CHVs to keep them up to date with the latest knowledge, techniques, and strategies to improve community health.

Table 4. Strategies and recommendations

\begin{tabular}{|c|c|}
\hline Concepts & Quotes \\
\hline $\begin{array}{l}\text { Strategies to } \\
\text { enhance } \\
\text { immunization } \\
\text { uptake }\end{array}$ & $\begin{array}{l}\text { "There are times we use the 'chest' (colloquial translation of 'force')... because } \\
\text { the parent will come here and tell me the child will not be immunized. As the } \\
\text { child is with me, I try to save the child's life so that they are not affected by the } \\
\text { parent's decision." KII, ECD provider }\end{array}$ \\
\hline \multirow[t]{3}{*}{$\begin{array}{l}\text { Strategies for } \\
\text { encouraging } \\
\text { male involvement }\end{array}$} & $\begin{array}{l}\text { "In a group like in the unit we have male CHVs. We go to public action days with } \\
\text { the men so that male caregivers can see truly this thing is not for women } \\
\text { only...."FGD, CHVs }\end{array}$ \\
\hline & $\begin{array}{l}\text { "I think maybe if they can be brought to the training and be told that being with } \\
\text { the child is not only for the mothers ... if they could be taught and be told that the } \\
\text { child belongs to both of them...and they should not leave the responsibility to } \\
\text { one person... it is also his responsibility to take care of the child." KII, ECD } \\
\text { teacher, Makutano }\end{array}$ \\
\hline & $\begin{array}{l}\text { "... when that problem arises, we use something like graduation at the end of the } \\
\text { year and then we tell them the importance of all the parents being committed to } \\
\text { their children... that a child does not belong to the mother alone or a father, but } \\
\text { they belong the community." KII, ECD provider }\end{array}$ \\
\hline $\begin{array}{l}\text { Recommendation } \\
\text { for CHV } \\
\text { motivation }\end{array}$ & $\begin{array}{l}\text { "What I think can be done so that CHVs improve their work, is at least to give } \\
\text { them motivation... they should be given so that they have the energy and the } \\
\text { heart to work more than how they are working now." FGD, CHVs, Tugumoi }\end{array}$ \\
\hline $\begin{array}{l}\text { Recommendation } \\
\text { for collaborative } \\
\text { partnerships }\end{array}$ & $\begin{array}{l}\text { "I also wish to recommend that the county and the national government have a } \\
\text { steering working group that oversees the implementation of the issues of ECD } \\
\text { for these children 0-36 months. In this way, we will not have duplication of roles } \\
\text { at the county and national levels. There should be a steering group which ... } \\
\text { could be meeting quarterly to evaluate the implementation." KII, policy } \\
\text { implementer, Eldama Ravine }\end{array}$ \\
\hline
\end{tabular}

\section{Opportunities for and existing gaps in program implementation}

The third area in which information was generated was in relation to opportunities for and existing gaps in implementation of the BFCI plus CCD intervention. This included a need to gain an understanding of the potential barriers and facilitators to program implementation.

\section{Potential facilitators for incorporating parental support for nurturing care into the BFCl}

One of the most important facilitators for incorporating parental support for nurturing care into the BFCl was the fact that the 'community was receptive and was willing to accept anything that would benefit them'as reported by the sub-County Community Health Strategist. The presence of the community health strategy and availability of functional community units with $\mathrm{CHVs}$ able to teach were also 
considered important facilitators for incorporating parental support for nurturing care into the $\mathrm{BFCl}$ (Table 5). This was especially so as $\mathrm{CHVs}$ reported that they highlighted and emphasized the importance of immunization, early breastfeeding initiation, and exclusive breastfeeding up to six months during the home visits.

Building on existing caregiver ECD knowledge and practices was considered a facilitator for the integration of parenting support for nurturing care into the BFCl. With regards to play and stimulation, $\mathrm{CHV}$ reported that they taught caregivers how to provide appropriate care to young children. They also provided information about children's developmental milestones and how play promotes proper child development. The nutrition-related services that mothers received from CHVs included demonstrations on how to position the baby during breastfeeding, how to prepare nutritious meals, information on how to grow their own vegetables around the home and the different types of foods that should be given to young children. CHVs also urged mothers to ensure that they fed children with pure fresh milk and to used clean containers for feeding. The childcare-related services that CHVs reported that they provided to mothers included visits to check on the child's height, weight, health and general growth, teaching mothers how to care for and handle their children and ensure proper grooming for the child. CHVs encouraged mothers to take their children to the clinic for regular check-ups and growth monitoring.

Primary caregivers corroborated what $\mathrm{CHVs}$ had mentioned and reported that they had been taught about the need to maintain their children's good health through immunization, use of insecticide-treated mosquito nets, proper hygiene, and sanitation (e.g., proper latrine use and critical times for handwashing) and appropriate health-seeking behavior. Caregivers were empowered through this information sharing process as it provided a critical avenue for them to provide support for the health aspects of nurturing care practices. Other topics that they mentioned included safeguarding the rights and ensuring the security of young children. The messages that caregivers received from CHVs were reinforced by other service providers which enhanced retention, and parents understood how to promote and enhance children's holistic development. The sub-county and county government officials reported that they made efforts to educate mothers and create awareness on the importance of vitamin A, deworming, hygiene, and sanitation among those with children attending ECD centers (Table 5). In addition, they provided vitamin A and deworming drugs to the children in ECD centers. The sub-county health department also made efforts to educate pregnant and new mothers on the important milestones that children should achieve, and how to check if the milestones had been achieved.

CHVs reported that some of them had participated in the earlier BFCl program which provided a solid foundation on which to build their support for incorporating parental support for nurturing care. The groups that were set up through the earlier intervention were still operational (Table 5). The CHVs who participated in the earlier BFCl intervention reported that caregivers were more knowledgeable on good care of their children, and that breastfeeding practices among mothers had improved. In addition, grandmothers also encouraged mothers to practice exclusive breastfeeding (EBF) for six months, and to practice complementary feeding thereafter. With regards to incorporating nurturing care into the $\mathrm{BFCl}$, $\mathrm{CHVs}$ and grandmothers believed that based on their previous experience, it would result in a community 
of people who would help mothers to promote the development of their children. They also mentioned that they expected to get a lot of advice on how to feed children, how to play with them and give them a good education.

Other stakeholders and organizations that were involved in ECD-related service provision and coordination among these different players enabled an integrated and multi-sectoral approach to promoting parenting support for nurturing care into the BFCl. For instance, ECD center providers reported that they taught mothers the importance of breastfeeding in the first six months, and of complementary feeding in subsequent months. An existing health program for young children also provided mobile phone messages on child growth and development to participating caregivers. Caregivers reported that they also received information on child development through messages on radio (Table 5). These are important platforms for providing constant reminders on how parents can support incorporation of nurturing care into the $\mathrm{BFCl}$.

Policy implementers mentioned that existing ECD-related policies included the BFCl and the MIYCN policies (Table 5). These policies have a direct impact on the growth and development of children as they targeted those under five years. The 'Malezi Bora' (which means 'appropriate nurturing') program has improved access to health services for expectant mothers and children under five and could be considered a facilitator to the integration of nurturing care into the $\mathrm{BFCl}$.

\section{Potential barriers to incorporating parental support for nurturing care into the BFCI}

As shown in Table 5, one of the barriers to integration reported was the fact that caregivers did not consider growth monitoring visits to the $\mathrm{MCH}$ clinics important after the child received their measles vaccination at the age of nine months. This suggested that caregivers did not really value the importance of continued clinic visits up to the age of 36 months. Another reported barrier was the fact that healthcare service providers did not seem willing to incorporate ECD counselling in their engagement with primary caregivers during the health facility visits. This unwillingness may have been related to the fact that they already felt overwhelmed by their current work responsibilities and did not want to be burdened further. The seeming lack of encouragement for promoting parental support for nurturing care at the health facilities which was manifested through the lack of play materials which children and their caregivers could engage with during waiting periods at the health facility visits was perceived as another barrier.

Participants reported that there was a challenge in upholding the need for participation of men in childcare provision as there was a general lack of male involvement in promoting optimal growth and development of young children. According to mothers, fathers did not engage in productive ventures and hence failed to provide financial support for their families. Some fathers would also not accompany their wives to the clinic as they perceived this to be solely the responsibility of other women. In the cases where fathers accompanied their wives, they would wait for them at the clinic gates. An ECD official pointed out that men seemed to have abdicated their responsibilities of providing for their families and being the main decision makers in the home. Alcoholism seemed to have rendered men unable to support 
their wives. The poor male involvement in childcare activities was a hindrance to enlisting their support for incorporation of nurturing care into the $\mathrm{BFCl}$.

Table 5. Facilitators and barriers 


\section{Concepts Quotes}

\section{Facilitators}

Complementary community strategy support

Existing relevant policies
"...I still believe that issues of ECD can be implemented very well through the community units because the CHVs are people who are based at the household level. So once you build their capacity, then you expect that thing to be rolled as you have told them." KII, sub-County Focal Person, Eldama Ravine

"...as a sub-County we benefited from the BFCl. We have the BFCl policy which ... takes into consideration the issue of child feeding up to 1000 days, the importance of child development and also, it articulates the issue of breastfeeding and weaning.." KII, ECD Director, Eldama Ravine
Integration with

existing

strategies

Information

from other

sources "...we have the immunization policy that recommends that children complete their immunization which should be done correctly. ... the MIYCN policy is also another one ... which takes care of the under-fives..." KII, ECD Coordinator, Eldama Ravine

"I have heard from radio stations that children should take millet. Several varieties of flour should be mixed. You can mix millet and maize then you grind them and prepare ugali using the mixed flour. Give that ugali to the child in the evening and also in the morning. According to the information, that ugali is very beneficial to the children. The radio was saying that flour gives the body energy" FGD, grandmothers, Makutano
Ongoing support
"When they came to us for the first time, they were able to even set up for us projects and to bring women together. We formed groups which are continuing up to now. Those women are still together, they are doing merry-go-round. Some have even started a project of rearing chicken for themselves and others are keeping beehives which benefits us a lot" FGD, CHVs, Eldama Ravine Hospital
Use of existing knowledge
"My work caring for grandchildren is... to talk to the parents, that is, my own children... Like we have been taught that we should not let them be fed things which they shouldn't be when they are still young, below the age of 6 months. After that, to ensure that they have been fed foods that are proper." IDI, grandmother, Kiptuno

\section{Barriers}

Lack of complete adherence to clinic visit schedule

"...after 6 months, that is, exclusive breastfeeding, whatever happens after weaning there is no follow up. We encourage mothers to bring their children for weighing up to 5 years but when a child has finished the 9-month immunization, you only meet with that mother when she is coming for her ANC services or you meet that particular mother when she brings that child for the 18-month measles jab...So actually there exists a big gap ...from ... 12 months to 36 they are not given any priority because they believe that after the immunization of the 9 months, the child now is safe" KII, ECD County Director, Baringo

Lack of stimulating play materials at health facilities

Inadequate staffing levels
"At the facility level or even at school, we need those children's activities, maybe with toys... So you come to our facility at the district hospital, there is nothing like that, it is only the doctor. The child is sick, and when the child cries, the only thing the doctor will tell the mother is 'calm the child down, give her the breast."' IDI, subCounty health management team member, Eldama Ravine

"One of the challenges is adequacy of personnel. Actually now currently what we have is fewer personnel in the field and this has impacted negatively on even health care delivery." KII, sub-County CHS 


\section{Discussion}

This feasibility study was part of a follow-up study of an earlier BFCl intervention and was conducted to provide a better understanding of the local contexts and cultural factors that influence development; user, stakeholder and service provider needs for incorporating parental support for nurturing care into the BFCl; and, to explore opportunities for and existing gaps in program implementation. Qualitative interviews among users, stakeholders and service providers provided extensive information on their understanding regarding ECD, beliefs around caregiving, needs at the different levels and potential barriers and facilitators.

\section{Knowledge, attitudes, and practices on ECD and early stimulation}

That caregivers considered ECD to encompass aspects of child growth, hygiene, feeding, and health demonstrated that they were aware that it comprised several domains. However, the missing components from the caregivers' understanding was that of early learning and stimulation and children's developmental progression. Knowledge deficits in the milestones that children should be able to achieve under different developmental categories have also been reported in a previous study in South Africa among caregivers of children under the age of six years (Meintjes \& Belkum, 2013). As with the current study, health workers were considered an important and trusted source of information on and support for ECD as they seemed to have a greater understanding of nurturing care (Meintjes \& Belkum, 2013). Caregivers spend a lot of time with their young children and are therefore important in providing support for incorporating nurturing care into the $\mathrm{BFCl}$. They are also able to contribute to children's desired developmental outcomes through timely identification of developmental delays. However, they can only do so if they are equipped with the necessary knowledge on nurturing care; a process which can be facilitated through $\mathrm{CHVs}$. Interventions in which caregivers are expected to play a major role should build on their existing knowledge to facilitate success. When caregivers feel that their importance is recognized, they are likely to take ownership of such interventions, which further facilitates sustainability (Iwelunmor et al., 2016).

Fathers reported a limited understanding of ECD, as they perceived it in terms of child behavior like crying and playing. Given that there are particular periods of early development when certain types of behavior are most helpful, it is critical to extend fathers' understanding of nurturing care. To the extent possible, fathers should also be involved in nurturing care activities to support the role that mothers play. This is particularly with regards to their engagement (direct interactions), availability (presence and accessibility), and responsibility (material provision) (Lamb, Pleck, Charnov, \& Levine, 1987) which have an impact on child outcomes. Fathers reported that they mainly engaged in outdoor play activities with their children, a finding which is corroborated by others who found that fathers tend to be more involved in "rough and tumble" play (e.g., Spetter, 2019). On the other hand, primary caregivers who were mostly 
mothers, commonly reported engaging in indoor activities and those which promoted independence in carrying out activities of daily living among children. As incorporating parental support for nurturing care into the $\mathrm{BFCl}$ is facilitated by interactions between children and their parents, the role of both parents remains very important.

\section{Contextual and cultural influences on child development and nurturing care practices}

The role of cultural beliefs that we identified seemed to be in influencing the differential treatment of children according to their gender, understanding events with an unknown cause as well as shaping gendered roles in the early care of children. Religious beliefs also seemed to have a strong influence on caregivers' healthcare seeking behaviors particularly in relation to medical treatment when children were unwell and use of preventative services such as immunization. Similar to our findings, beliefs which have been reported in other studies prescribed expected behavior according to gender (Nsamenang, 1987) and encouraged 'hiding' away a breastfeeding mother from the 'evil eye' (Kavle et al., 2019). It could be that, as has been mentioned in previous studies (Cabrera, Fitzgerald, Bradley, \& Roggman, 2007), mothers are expected to assume responsibility of primary caregiving in the early years. As has been alluded to in a study among participants in a rural area in Burkina Faso (Hollowell et al., 2019), the clear separation of caregiving tasks and material provision could be informed by gendered divisions of household roles and labor. With regards to healthcare seeking behaviors, a systematic review of barriers to improve childhood health and survival noted that misconceptions about childhood immunization which may arise from religious beliefs were a major hindrance to effective utilization of immunization services (Bangura, Xiao, Qiu, Ouyang, \& Chen, 2020). Finding ways to dialogue with participants on positive traditional practices that can be sustained, such as the reliance on multiple caregivers for the care of young children and recognition of the critical role of elders and traditional healers, is important in incorporating parental support for nurturing care into the $\mathrm{BFCl}$. Further, the use of a community-initiated mechanism such as mother-to-mother groups could provide a suitable forum for discussions on how to deal with myths and misconceptions which are detrimental to ECD practices.

To enhance integration, it is essential to empower caregivers, families, and communities so that they can make use of existing services, demand more and better services and improve their nurturing care activities (UNICEF, World Bank Group, World Health Organization, ECD Action Network, \& Partnership for Maternal, 2019). Such a process will also enable them to eliminate harmful cultural practices, and maintain those that are considered beneficial to promoting nurturing care.

\section{User, stakeholder, and service provider needs for incorporating parental support for nurturing care into the $\mathrm{BFCl}$}

The needs reported by multiple participants highlighted the importance of being sensitive to community requirements, particularly among those living in disadvantaged settings, before compelling them to support the implementation of a specific program. For instance, children's access to quality care is compromised when caregivers themselves do not have good health. The finding that children with disabilities remained ignored suggested the need for inclusive programs in which children are not left out 
on the basis of their physical conditions or health status. This would link in very closely with the recommendation of the Lancet 2016 ECD Series on inclusive policies and initiatives for children with disabilities to maximize returns from early interventions (Black et al., 2017). Integration of nurturing care into the $\mathrm{BFCl}$ is likely to benefit those who are most vulnerable, and children with disabilities are among those who stand to benefit the most.

Participants made some recommendations on how to incorporate parental support for nurturing care into the BFCl which concerned inclusion of children with disabilities, community outreaches, and family counselling programs. Other recommendations were geared towards encouraging greater male involvement. These recommendations illustrated that participants were well aware of the need to deal with their unmet needs, while at the same time, were willing to provide 'home grown' solutions, which could be harnessed to improve support for early child development in rural Kenya.

\section{Opportunities for and existing gaps in program implementation}

There were generally positive feelings about integrating nurturing care into the $\mathrm{BFCl}$ as participants believed that it would amplify the effects of the earlier intervention. For instance, CHVs mentioned that it would result in greater knowledge on and support for ECD within the community. CHVs therefore facilitated the incorporation of nurturing care activities into the $\mathrm{BFCl}$ as they seemed to understand the importance of promoting the holistic development of children.

One important facilitative factor was the existence of a robust community health strategy which could be used to reach out to families with the relevant messages on a regular basis. The wide range of services provided by different players illustrated that cooperation among several related departments (such as health, education, and agriculture) would ensure smooth integration for the holistic development of children. Some of these services were targeted at mothers, while others were targeted directly at the child. It is imperative that the different services are provided in a manner such that there are no duplicative roles, and that each service provides an additive advantage. Identifying supportive frameworks is an important consideration to make when planning integrated interventions as these are critical determinants of success or failure. In addition, establishing how well existing platforms work in supporting integrated interventions is a good starting point for identifying how they could be used more effectively. Finding a feasible route for delivery that builds on existing systems and costs, rather than adding new infrastructure is therefore an important consideration in incorporating parental support for nurturing care into the $\mathrm{BFCl}$.

Noteworthy is that the lack of male involvement was cited as a major barrier to incorporating parental support for nurturing care to enhance optimal growth and development of children. And yet, as has been mentioned earlier, successful integration will only happen if all those who come into contact with young children provide full support for the various activities. Some of the gaps that were revealed through the interviews with policymakers illustrated that children at some specific ages may not be receiving optimal care and attention. For instance, after nine months, parents may lose out on the benefits of regular growth monitoring for their children because they stop visiting the clinics. Although we could posit that 
mothers may not really understand the importance of regular growth monitoring hence the cessation of facility visits after the last immunization, it is worthwhile to seek a better understanding of why this is the case. In addition, there is need to identify strategies to encourage mothers to maintain clinic visits until the age of five years (and this is recommended within the Kenyan health system) in order to support better planning of services. Other gaps are with regards to the provision of services which may be less than optimal as service providers may not be up to date with the latest information. These gaps suggest that educational campaigns could be used to increase knowledge about the benefits of growth monitoring beyond the immunization visits. Routine health encounters provide opportunities for healthcare providers to encourage incorporation of parental support for nurturing care into the BFCl. Further, growth monitoring should encompass age-appropriate counselling as these visits could serve as a platform to support interventions and services that incorporate nurturing care (UNICEF et al., 2019).

Policy makers were not able to identify any ECD-related policies that had been formulated within the country. It is important that efforts are made to develop policies directly related to nurturing care as this would help highlight the importance of the ECD sector. Given that ECD was devolved to the county level, there are efforts by different counties to develop their own ECD policies which would provide guidelines for incorporating parental support for nurturing care through implementation of actions to promote the holistic growth and development of young children. However, these would be better coordinated if there was a national structure to facilitate this.

\section{Strengths and limitations of the study}

One strength of the current study was the inclusion of a wide range of participants who provided different perspectives. Capitalizing on relationships that we had already formed in the community through the earlier $\mathrm{BFCl}$ intervention reduced the resources required to mobilize this range of study participants. Moreover, the qualitative design enabled us to capture in-depth information on participants' perceptions of their role in promoting the incorporation of parental support for nurturing care into the BFCl. The inclusion of primary caregivers as major participants is both a strength and a limitation. On the one hand, primary caregivers are considered a reliable source of information on nurturing care practices and their influences, as they spend a significant part of the day with young children. However, it is also possible that primary caregivers may have wanted to present themselves in the best possible light due to social desirability, which may influence the accuracy of information reported. The previous delivery of the $\mathrm{BFCl}$ intervention by our team may have compounded this further because participants may have focused on reporting behaviors consistent with those that the $\mathrm{BFCl}$ promotes. The limitations notwithstanding, the study makes a unique contribution to the literature on considerations to be made in incorporating parental support for nurturing care into existing national nutrition programs such as the $\mathrm{BFCl}$.

\section{Conclusion and future directions}

Overall, our findings suggested that whereas participants did not have all the necessary information on how to incorporate parental support for nurturing care into the $\mathrm{BFCl}$, there were opportunities to increase their level of knowledge. Moreover, even though they engaged in some activities with the children, they did 
not seem to understand their role in stimulating young children's development through these activities. The needs mentioned by participants did not seem to be a hindrance to incorporating parental support for nurturing care as participants themselves were able to suggest solutions. Consideration of the cultural traditions and beliefs that may impact the acceptability of an integrated intervention to improve nurturing care as well as the involvement of fathers into nurturing care are critical. The presence of a robust community strategy linking relevant departments and coordinated from the national level provides a good platform for enhancing the sustainability of a program to incorporate nurturing care into the $\mathrm{BFCl}$. Future programs could consider incorporation of messages on positive parenting. Champion caregivers supported by community support groups could also be engaged as models of incorporating parental support for nurturing care into the $\mathrm{BFCl}$ to ensure inclusion of caregivers other than mothers into the program.

\section{Declarations}

The authors have no conflict of interest to declare.

The successful outcome of this project was made possible through the support and guidance from many individuals and teams. The research team thanks all the study participants for their contribution to the success of the study. We also acknowledge the support of staff from the Nutrition and Child Health Departments within the Ministry of Health at the sub-County, County and National levels for their guidance and input during the implementation of the project. We are also grateful for the guidance we received from the PATH team with regards to the implementation of the CCD package. This study was supported through funding from the British Academy.

\section{References}

Bangura, J. B., Xiao, S., Qiu, D., Ouyang, F., \& Chen, L. (2020). Barriers to childhood immunization in subSaharan Africa: A systematic review. BMC Public Health, 20(1), 1108. doi:10.1186/s12889-020-09169-4

Black, M. M., Walker, S. P., Fernald, L. C. H., Andersen, C. T., DiGirolamo, A. M., Lu, C., . . GranthamMcGregor, S. M. (2017). Early childhood development coming of age: science through the life course. The Lancet, 389(10064), 77-90. doi:10.1016/S0140-6736(16)31389-7

Cabrera, N. J., Fitzgerald, H. E., Bradley, R. H., \& Roggman, L. (2007). Modeling the dynamics of paternal influences on children over the life course. Applied Developmental Science, 11, 185-189.

doi:10.1080/10888690701762027

Core Group Community Health Network. (2012). The Baby Friendly Hospital Initiatives. Retrieved from http://www.coregroup.org/component/content/article/22-equity/262-thebaby-friendly-communityinitiative 
Gale, N. K., Heath, G., Cameron, E., Rashid, S., \& Redwood, S. (2013). Using the framework method for the analysis of qualitative data in multi-disciplinary health research. BMC Medical Research Methodology, 13, 117. Retrieved from http://www.biomedcentral.com/1471-2288/13/117

Grantham-McGregor, S. M., Fernald, L. C. H., Kagawa, R. M. C., \& Walker, S. P. (2014). Effects of integrated child development and nutritioninterventions on child development and nutritional status. Annals of the New York Academy of Sciences, 1308, 11-32. doi:10.1111/nyas.12284

Hollowell, J., Dumbaugh, M., Belem, M., Kousse, S., Swigart, T., Korsaga, C., . . Hill, Z. (2019).

'Grandmother, aren't you going to sing for us?' Current childcare practices and caregivers' perceptions of and receptivity to early childhood development activities in rural Burkina Faso. BMJ Global Health, 4(e001233). doi:10.1136/bmjgh-2018-001233

Iwelunmor, J., Blackstone, S., Veira, D., Nwaozuru, U., Airhihenbuwa, C., Munodawafa, D., ... Ogedegebe, G. (2016). Toward the sustainability of health interventions implemented in sub-Saharan Africa: a systematic review and conceptual framework. Implementation Science, 11(1), 43. doi:10.1186/s13012016-0392-8

Kavle, J. A., Ahoya, B., Kiige, L., Mwando, R., Olwenyi, F., Straubinger, S., \& Gath, C. M. (2019). BabyFriendly Community Initiative-From national guidelines to implementation: A multisectoral platform for improving infant and young child feeding practices and integrated health services. Maternal \& Child Nutrition, 15(e12747).

Kavle, J. A., \& Ahoya, B. M. (2019). Baby Friendly Community Initiative (BFCI): Implementation Experience from Kenya. Retrieved from

Kenya National Bureau of Statistics (KNBS), Ministry of Health/Kenya, National AIDS Control Council/Kenya, Kenya Medical Research Institute, \& National Council for Population, a. D. K. (2015). Kenya Demographic and Health Survey 2014. Retrieved from Rockville, MD, USA:

Kimani-Murage, E. W., Kimiywe, J., Kabue, M., Wekesah, F., Matiri, E., Muhia, N., . . McGarvey, S. T. (2015). Feasibility and Effectiveness of the Baby Friendly Community Initiative in Rural Kenya: Study Protocol for a Randomized Controlled Trial. Trials, 16, 431. doi:10.1186/s13063-015-0935-3

Kimani-Murage, E. W., Kimiywe, J., Mutoro, A. N., Wilunda, C., Wekesah, F. M., Muriuki, P., . . Griffiths, P. L. (2021). Effectiveness of the baby-friendly community initiative on exclusive breastfeeding in Kenya. Maternal and Child Nutrition, e13142. doi: https://doi.org/10.1111/mcn.13142

Lamb, M. E., Pleck, J. H., Charnov, E. L., \& Levine, J. A. (1987). A biosocial perspective on paternal behavior and involvement. In J. B. Lancaster, J. Altmann, A. S. Rossi, \& L. R. Sherrod (Eds.), Parenting across the life span: Biosocial dimensions (pp. 111-142). Hawthorne, NY: Aldine Publishing Co. 
Maingi, M., Kimiywe, J., \& Iron-Segev, S. (2018). Effectiveness of Baby Friendly Community Initiative (BFCl) on complementary feeding in Koibatek, Kenya: a randomized control study. BMC Public Health, 18(600). doi:10.1186/s12889-018-5519-1

Meintjes, J. S., \& Belkum, C. v. (2013). Caregivers' knowledge regarding early childhood development in Soshanguwe, South Africa. Africa Journal of Nursing and Midwifery, 15, 170-186.

Ministry of Health (MOH) Kenya. (2016). Baby Friendly Community Initiative: Implementation Guidelines. Retrieved from Nairobi, Kenya: http://pdf.usaid.gov/pdf_docs/PA00N1CF. pdf

Nsamenang, B. A. (1987). A West African Perspective. In M. E. Lamb (Ed.), The Father's Role CrossCultural Perspectives. Hillsdale, New Jersey: Lawrence Erlbaum.

Powell, C., Baker-Henningham, H., Walker, S., Gernay, J., \& Grantham-McGregor, S. (2004). Feasibility of integrating early stimulation into primary care for undernourished Jamaican children: cluster randomised controlled trial. BMJ, 329. doi:10.1136/bmj.38132.503472.7C

Spetter, D. (2019). The Role of Fathers in Childhood Development. Faculty Insight.

Thomas, D. R. (2006). A General Inductive Approach for Analyzing Qualitative Evaluation Data. American Journal of Evaluation, 27(2), 237-246. doi:10.1177/1098214005283748

UNICEF. (2015). Care for Child Development Package. Retrieved from New York, NY:

UNICEF, World Bank Group, World Health Organization, ECD Action Network, \& Partnership for Maternal, Newborn and Child Health. (2019). Operationalizing Nurturing Care for Early Childhood Development: The role of the health sector alongside other sectors and actors. Retrieved from Geneva, Switzerland:

Walker, S. P., Powell, C., Chang, S. M., Baker-Henningham, H., Grantham-McGregor, S., Vera-Hernández, M., \& Bóo, F. L. (2015). Delivering Parenting Interventions through Health Services in the Carribean: Impact, Acceptability and Costs. Retrieved from New York:

World Health Organization, \& UNICEF. (2009). Baby Friendly Hospital Initiative: revised, updated and expanded for integrated care. Retrieved from New York, NY:

World Health Organization, \& UNICEF. (2018). Global Breastfeeding Scorecard, 2018: Enabling women to breastfeed through better policies and programmes. Retrieved from Geneva, Switzerland: 